\title{
CS directionality and intensity in avoidance learning and extinction
}

\author{
J. C. WHITTLETON, D. J. KOSTANEK AND J. M. SAWREY \\ SAN JOSE STATE COLLEGE
}

\begin{abstract}
Rats were given avoidance conditioning and extinction in a shuttlebox with simple and complex directional cue stimuli. The hypotheses were: increasingly complex cue stimuli would produce faster learning and slower extinction; and avoidance from CS source would produce faster learning and slower extinction. Results were analyzed by 2-way analysis of variance. All hypotheses were supported at $p<.01$. The results were interpreted in terms of Mowrer's (1960) fear-reduction theory and a drive-stimulus-reduction model.
\end{abstract}

\section{Int roduction}

McAdam (1964), has reported on the effect of directionality of CS on the acquisition of avoidance behavior. Ss trained to avoid shock by running from a tone learned faster and responded more consistently than Ss trained to avoid by running toward a tone. The effects of stimulus complexity (Pavlov, 1927) and directionality (McAdam, 1964) on acquisition have been reported but the effects on extinction are vague.

The present investigation was undertaken to determine the effects of both complexity and directionality of cue stimulus on acquisition and extinction of a conditioned avoidance response. The hypotheses to be tested are: 1. Rate of learning for Ss trained to avoid by running from the source of the CS will be significantly faster than for Ss trained to avoid by approaching the CS source.

2. Rate of learning of the avoidance response will increase as CS saliency and complexity are increased.

3. Rate of extinction of the avoidance response will be significantly greater for groups trained to avoid by running toward the CS source.

4. Rate of extinction of the avoidance response will decrease as CS saliency and complexity are increased.

\section{Method}

Subjects: Ss were 30 experimentally naive, male, Long-Evans rats, 90 days of age.

Apparatus: The apparatus used was a modified version of the Miller-Mowrer shuttlebox. The box was 6 in wide, 36 in long, and 8-1/2 in high, with a brass rod grid floor. Wooden interior walls were painted flat black to reduce directional cues within the apparatus. The front of the box was fitted with a one-way mirror. A flat black, removable, constantly illuminated hood of Masonite was used to cover the box. Illumination level within the shuttlebox with the hood in place, light on and under darkened experimental conditions was constantat 2-1/2 cp at points 2 in from either end and 2 in above the floor, and was $4 \mathrm{cp}$ at the center of the box. All illumination measures were taken with a Weston Foot-Candle Meter, mod. 614.

US was 65 volts of direct current delivered to the grid bars through an 8-bar grid scrambler. Shock was of the constant voltage type. Ss provided the only circuit resistance. The grid scrambler was located below the center of the apparatus. Its rhythmical clicking (about $68 \mathrm{db}$ intensity) provided a masking noise.

CSs were a light and a buzzer. The light cue was provided by five 6-w unfrosted candelabra-base lamps located at each end, thus providing a directional cue. The lights produced a constant intensity of $40 \mathrm{cp}$ at a point 2 in above the grid and 2 in from the end of the box and $12 \mathrm{cp}$ when measured at the center of the box.

The auditory cue was provided by two buzzers hung by rubber bands 2 in above the grid on the ends of the shuttlebox. Intensity of the sound, 2 in above the grid, and 2 in from the end of the shuttlebox, was $72 \mathrm{db}$ and at the center of the apparatus was $60 \mathrm{db}$. Auditory cues were measured by a General Sound-Survey Meter, type 1555-A.

Stimulus presentation was automatically controlled by a series of capacitor-discharge interval timers, placed outside the experimental room. Stimulus offset was manually controlled by the experimenter. Latencies were measured by means of a Hunter Klockcounter, mod. 120A.

Procedure: Ss were randomly assigned to one of six equal training groups. With the exceptions of direction and CS type, all groups were given identical training as follows: Each $S$ was placed in one end of the shuttlebox facing the center and allowed 2 min. adaptation time. At the end of the $2 \mathrm{~min}$. period, the CS was turned on, followed in $5 \mathrm{sec}$. by the presentation of the US. CS continued throughout US presentation until both were response terminated. Intertrial interval was 25 sec. for all groups. Ss were given trials in blocks of 50 at $24 \mathrm{hr}$. intervals. Training criterion was set at 9 correct responses out of any block of 10 trials.

Extinction training was started as soon as acquisition criterion was met with no break between training and extinction. Extinction trials were exactly the same as training trials with the exception that no shock was presented. Criterion for an extinction trial was considered as a response latency greater than the CS-US interval (5 sec.). Ss were considered extinguished when they failed to respond within the $5 \mathrm{sec}$. interval 
on 9 out of any block of 20 trials. A maximum of 200 extinction trials was given in blocks of 50 per $24 \mathrm{hr}$. interval. Scoring was based on number of trials required to reach criterion and number of trials from the last escape response to reach extinction. Response latencies were taken to determine whether the response was an escape or an avoidance.

\section{Results}

Number of trials to training criterion was treated as a 2 by 3 factorial analysis of variance for directionality and CS strength. Avoidance from the CS source produced significantly faster acquisition $(F=14.22, \mathrm{df}=$ $1 / 24, \mathrm{p}<.005)$. Increasing CS complexity produced faster learning $(\mathrm{F}=16.46, \mathrm{df}=2 / 24, \mathrm{p}<.005)$. An interaction effect was found $(F=4.08, d f=2 / 24, p<.05)$.

A 2 by 3 factorial analysis of trials to extinction revealed that responding from CS source produced significantly slower extinction $(F=17.76, d f=1 / 24, p<$ $.005)$. The more salient the cue (or cues), the more resistant to extinction was the response $(F=5.64, \mathrm{df}=$ $2 / 24, p<.01)$. No significant interaction was found $(\mathrm{F}=1.57, \mathrm{df}=2 / 24, \mathrm{p}>.20)$. All means are presented in Table I.

\section{Diseussion}

The hypotheses proposed for this investigation were supported experimentally.

Groups trained to avoid by running from the CS learned much more rapidly and extinguished much more slowly than groups avoiding toward the CS. Mowrer (1960) stated that a fear response is classically conditioned to a neutral cue stimulus as a function of its contiguity with the US on shock trials. The implication is that the cue itself takes on the quality of a noxious stimulus. Increasing the intensity of the cue stimuics during the avoidance response would then have the effect of increasing fear, while running from, or decreasing intensity of the CS should produce a fear decrement.

The CS directionality results may also be interpreted in approach-avoidance conflict terms. Ss trained to avoid shock by running toward the stimulus to which fear has been conditioned may be in a conflict situation. There is a tendency to approach the safe side of the apparatus, and a conflicting tendency to avoid the increasing intensity of the fear inducing CS.

Increasing stimulus complexity and saliency increased rate of learning. Mowrer \& Solomon (1954) have suggested that fear is conditioned to all stimuli present at the time of CS onset. Increasing CS complexity should result in proportionately more of the shock induced fear being conditioned to the CS, and proportionately less to the apparatus cues, and thus, less
TABLE I MEAN TRIALS TO AVOIDANCE

\begin{tabular}{lrcc} 
& LIGHT & BUZZER & LITE-BUZZER \\
\hline TOWARD CS & 175.8 & 51.0 & 55.4 \\
FROM CS & 68.8 & 39.0 & 27.2 \\
\hline
\end{tabular}

MEAN TRIALS TO EXTINCTION

\begin{tabular}{lrcc} 
& LIGHT & BUZZER & LITE-BUZZER \\
\hline TOWARD CS & 5.8 & 22.0 & 27.4 \\
FROM CS & 33.8 & 53.8 & 95.0 \\
\hline
\end{tabular}

generalization of fear extinction to the stimuli present during CS-US interval should occur. Fear conditioned to more complex CS cues is preserved from extinction and a greater portion of the conditioned fear is now available to produce the response on subsequent CS presentations.

Examination of the training means (Table I) indicates that the interaction shown in acquisition seems to be an effect of the low salience of the light CS cue combined with the inhibitory effects of responding toward the CS source. Only one $S$ of the group met the training criterion within the 200 trial limit.

Ss responding toward the CS extinguished significantly faster than those running from the CS. This can be interpreted within drive-stimulus-reduction theory. For Ss avoiding from a CS, stimulus intensity is strongest at the starting point, and diminishes as the $\mathrm{S}$ runs toward the "safe" side. If CS fear intensity is proportional to CS strength, then less of the fear conditioned to the CS undergoes an extinction effect on each nonreinforced avoidance trial.

In avoiding toward CS source, at the time of onset, a low level of fear, due to the distance from the CS, is generated and as the $\mathrm{S}$ begins a skeletal response, fear increases proportionately to the increasing intensity of the CS. Therefore, at CS offset, fear is at a high level, and a nonreinforced trial should cause a greater fear decrement, thus giving a greater extinction effect.

\section{Referemees}

McAdam, D. Effects of positional relations between subject, CS and US on shuttlebox learning in cats. J. comp. physiol. Psychol., 1964, 58, 320-304.

Mowrer, O. H. Learning theory and behavior. New York: John Wylie and Sons, 1960.

Mowrer, O. H., \& Solomon, L. N. Contiguity vs. drive-reduction in conditioned fear: the proximity and abruptness of drive-reduction. Amer. J. Psychol., 1954,67, 15-25.

Pavlov, I. P. Conditioned reflexes, (G. V. Anrep, trans.). London: Oxford University Press, 1927. 